\title{
Which is preferable for orthostatic hypotension diagnosis in older adults: active standing test or head-up tilt table test?
}

This article was published in the following Dove Press journal:

Clinical Interventions in Aging

25 January 2017

Number of times this article has been viewed

\author{
Ali Ekrem Aydin' \\ Pinar Soysal ${ }^{2}$ \\ Ahmet Turan Isik' \\ 'Center for Aging Brain and Dementia, \\ Department of Geriatric Medicine, \\ Faculty of Medicine, Dokuz Eylul \\ University, Izmir, Turkey; ${ }^{2}$ Kayseri \\ Education and Research Hospital, \\ Geriatric Center, Kayseri, Turkey
}

Background: Correct evaluation of orthostatic hypotension $(\mathrm{OH})$ is crucial in geriatric practice, since $\mathrm{OH}$ is associated with mortality and morbidity. The study aimed to determine the most appropriate method for measuring blood pressure in transition from supine to upright position in order to diagnose $\mathrm{OH}$ in older adults.

Methods: Active standing test (AST) and head-up tilt table (HUT) test as well as comprehensive geriatric assessment (CGA), including mini-mental state examination or the cognitive state test, mini-nutritional assessment, basic and instrumental activities of daily living, and Tinetti performance-oriented mobility assessment indexes, were performed in 290 geriatric patients. Results: The prevalence of OH during HUT and AST was $19 \%$ and $37 \%$, respectively. In patients with $\mathrm{OH}$ during HUT, the frequency of dementia and recurrent falls were higher $(P<0.05)$; on the other hand, the levels of serum vitamin D and albumin and estimated glomerular filtration rate were lower $(P<0.05)$. However, all these parameters for $\mathrm{OH}$ during AST were not significant $(P>0.05)$. Comparison of the groups according to CGA measurements revealed significant differences in terms of cognition, nutritional status, activities of daily life, and balance function in patients with $\mathrm{OH}$ only during HUT $(P<0.05)$, but not during AST $(P>0.05)$. The sensitivity, specificity, positive predictive value, and negative predictive values of AST were $49.0 \%$, $65.5 \%, 25.0 \%$, and $84.6 \%$ respectively, according to HUT.

Conclusion: The results suggest that orthostatic blood pressure changes determined by HUT might be of higher clinical significance than that by AST in older adults. It might be important that the evaluation of $\mathrm{OH}$ by HUT should be included in daily geriatric practice.

Keywords: active standing test, head-up tilt table, orthostatic hypotension, diagnosis

\section{Introduction}

Orthostatic hypotension $(\mathrm{OH})$ is a common clinical problem among older adults, which affects nearly $25 \%-30 \%$ of this population. ${ }^{1,2}$ Common comorbidities, such as diabetes mellitus (DM), dehydration, and malnutrition, and frequent use of diuretics, antihypertensive drugs, levodopa, and benzodiazepines might lead to $\mathrm{OH}^{3}$ that may cause dizziness, blackouts, blurred vision, balance impairment, recurrent falls, dyspnea, angina pectoris, paracervical and lumbar pain, weakness, and nausea. ${ }^{4,5}$ However, one-third of elderly adults with $\mathrm{OH}$ are asymptomatic. ${ }^{6}$ The correct diagnosis of $\mathrm{OH}$ in the elderly is of great importance; previous studies demonstrated association of $\mathrm{OH}$ with mortality, ischemic stroke, falls, cognitive failure, impaired sleep quality, depression, renal failure, and cognitive impairment in older adults., ${ }^{2,-12}$ Therefore, evaluation of orthostatic blood pressure (BP) changes should be a part of the comprehensive geriatric assessment (CGA). ${ }^{13}$ 
According to the consensus statement on the detection of $\mathrm{OH}$ published in 1996, the diagnosis of $\mathrm{OH}$ is made in the event of at least $20 \mathrm{mmHg}$ decrease in systolic blood pressure and/or at least $10 \mathrm{mmHg}$ decrease in diastolic blood pressure within the first $3 \mathrm{~min}$ after standing. ${ }^{14}$ However, there is no consensus on the optimum method for diagnosis of $\mathrm{OH}$.

Active standing test (AST) has been used in the majority of studies; ${ }^{15-18}$ however, many older adults cannot change their positions easily during transition from supine to upright position, because of existing comorbidities and immobility. Therefore, the BP change during the AST may not be evaluated objectively. On the other hand, an acceptable alternative to AST is head-up tilt table (HUT) test, which may be a more convenient method to detect $\mathrm{OH}$ in the elderly, ${ }^{19}$ but the data are limited.

The aim of this study was to determine the optimum evaluation of measurement of orthostatic BP changes in older adults by comparing the results of AST and HUT.

\section{Patients and methods \\ Patients}

A total of 290 elderly patients, who were admitted to the geriatric clinic in a university hospital between January 2014 and May 2015, were included in this prospective and crosssectional observational study. In addition to CGA, HUT and AST were performed in those geriatric patients after obtaining their informed written consents.

\section{Inclusion criteria}

All patients in the age group of 65 years or older admitted to the geriatric outpatient clinic for any reason were included in the study.

\section{Exclusion criteria}

Patients with the following conditions were excluded: severe anemia $(<10 \mathrm{~g} / \mathrm{dL})$, severe metabolic acidosis, electrolyte imbalance, severe kidney or heart failure, hypotensive shock, coma, severe mitral valve or aortic valve stenosis, tachycardia, severe proximal cerebral artery stenosis, severe coronary artery disease, prior stroke or myocardial infarction in the past 7 days, lower extremity fractures, all of which are the contraindications of HUT, were excluded. ${ }^{20}$ Additionally, patients who cannot stand up actively by themselves or who were immobile were not included in the study. Consequently, 290 patients were available for study analysis.

\section{BP measurements}

\section{AST measurements}

The first BP measurement was taken following 5 min of rest at the lying position; afterward the patients were raised upright and the measurement was repeated on the same arm, at the 3 rd minute, using a mercury sphygmomanometer with an appropriately sized cuff. ${ }^{14}$

\section{HUT measurements}

Standardized tilt table was used during HUT (G-71 Tilt table; Gemesan, Istanbul, Turkey). BP measurement was taken following $5 \mathrm{~min}$ of rest at the lying position; afterward the patients were raised upright at $60^{\circ}-80^{\circ}$ and the measurement was repeated on the same arm at the $3 \mathrm{rd}$ minute using a patient monitor with an appropriately sized cuff (M69S Patient monitor; Biolight, Zhuhai, People's Republic of China). During HUT, the patients were asked for $\mathrm{OH}$ symptoms. ${ }^{14}$

$\mathrm{OH}$ diagnosis was defined as a drop of at least $20 \mathrm{mmHg}$ in systolic blood pressure and/or $10 \mathrm{mmHg}$ in diastolic blood pressure upon the change in position in both AST and HUT. ${ }^{14}$

\section{Comprehensive geriatric assessment}

Demographic data (age, gender, and education status) of the patients, history of falls (according to the information obtained from the patient or patient's relatives, presence of more than one fall not associated with seizure or acute stroke within the past year), and personal history of chronic diseases (hypertension, DM, coronary artery disease, congestive heart failure, peripheral vascular disease, dementia, hyperlipidemia, cerebrovascular disease, depression, polypharmacy, and tobacco use) were questioned in detail. In addition, for each patient, scores of the mini-mental state examination or the cognitive state test, ${ }^{21}$ mini-nutritional assessment, basic and instrumental activities of daily living, and Tinetti performance-oriented mobility assessment indexes were also recorded. Body mass index was calculated as body weight in kilograms divided by the squared value of body height in meters $\left(\mathrm{kg} / \mathrm{m}^{2}\right)$.

\section{Laboratory findings}

Certain laboratory tests were performed to assess the biochemical, metabolic, and nutritional status of patients in our geriatric department. Thus, hospital laboratory records were also obtained for complete blood count, kidney and liver functions, cholesterol levels, thyroid-stimulating hormone, glycated hemoglobin, vitamin B12, folic acid, and vitamin D levels. All these biochemical tests were carried out on Diagnostic Modular Systems autoanalyzer (E170 and P800 Diagnostic modular systems; Roche, Basel, Switzerland).

\section{Statistical analysis}

Continuous variables were expressed as mean \pm standard deviation and evaluated by the Kolmogorov-Smirnov test 
for normal distribution. Continuous variables with normal distribution were evaluated with independent sample $t$-test whereas those with abnormal distribution were post hoc evaluated by the Mann-Whitney $U$ test. Differences in proportions were evaluated by the chi-square test and Fisher's exact test. The differences between dependent categorical variables were evaluated by McNemar's test. Kappa value was used for consistency. Probabilities $<0.05$ were considered significant. All statistical analyses were performed using Statistical Package for the Social Sciences (SPSS) 15.0 (SPSS Inc., Chicago, IL, USA). Adequate sample size was calculated (244 patients for $95 \%$ confidence interval).

\section{Ethics}

The investigation conformed to the Declaration of Helsinki and was approved by the local ethics committee (Dokuz Eylul University Ethics Committee, Izmir, Turkey, 2013/23-08).

\section{Results}

The prevalence of $\mathrm{OH}$ during HUT and AST was 19\% and $37 \%$, respectively. The differences between the groups with and without $\mathrm{OH}$ during HUT and AST are demonstrated in Table 1 .

The frequency of dementia and recurrent falls were higher in the group with $\mathrm{OH}$ during HUT $(P<0.05)$. The serum levels of vitamin D and albumin and estimated glomerular filtration rate were lower in those with $\mathrm{OH}$ during HUT $(P<0.05)$. It was determined that all these parameters for $\mathrm{OH}$ during AST were not significant ( $P>0.05$; Table 1). Comparison of the groups according to CGA measurements revealed no differences in terms of cognition, mood, nutritional status, activities of daily life, and balance function in patients with $\mathrm{OH}$ only during AST $(P>0.05)$, whereas the cognitive state test, Tinetti performance-oriented mobility assessment, mini-nutritional assessment, basic activity of daily living, and instrumental

Table I Patient characteristics according to HUT and AST

\begin{tabular}{|c|c|c|c|c|c|c|}
\hline & \multicolumn{3}{|l|}{ HUT } & \multicolumn{3}{|l|}{ AST } \\
\hline & $\begin{array}{l}\text { OH(+) } \\
n=55(19 \%)\end{array}$ & $\begin{array}{l}\text { OH(-) } \\
n=235(81 \%)\end{array}$ & $P$-value & $\begin{array}{l}\mathrm{OH}(+) \\
\mathrm{n}=108(37 \%)\end{array}$ & $\begin{array}{l}\mathrm{OH}(-) \\
n=182(63 \%)\end{array}$ & P-value \\
\hline Age (years) & $78.7 \pm 8.1$ & $73.9 \pm 8.6$ & $<0.001$ & $75.7 \pm 8.3$ & $74.2 \pm 9$ & 0.167 \\
\hline Sex (female/male), n & $30 / 25$ & $143 / 92$ & 0.391 & $58 / 50$ & $1 \mid 4 / 68$ & 0.152 \\
\hline $\mathrm{BMI}\left(\mathrm{kg} / \mathrm{m}^{2}\right)$ & $27.8 \pm 5.4$ & $28.4 \pm 4.9$ & 0.440 & $28.2 \pm 5.5$ & $28.4 \pm 4.8$ & 0.705 \\
\hline Polypharmacy ( $\geq 5$ drugs) (\%) & 45.5 & 34.6 & 0.133 & 40.4 & 34.8 & 0.342 \\
\hline Number of drugs used & $5.2 \pm 2.7$ & $4.7 \pm 3.0$ & 0.286 & $5.1 \pm 2.9$ & $4.6 \pm 2.9$ & 0.151 \\
\hline Recurrent falls (\%) & 36.4 & 18.5 & 0.004 & 21.7 & 22 & 0.947 \\
\hline \multicolumn{7}{|l|}{ Comorbidities (\%) } \\
\hline Dementia & 40 & 24 & 0.017 & 43.6 & 35.1 & 0.184 \\
\hline COPD & 3.6 & 11.6 & 0.078 & 10.3 & 10.1 & $0.95 I$ \\
\hline DM & 32.7 & 24 & 0.184 & 32.7 & 22.3 & 0.054 \\
\hline Hypertension & 67.3 & 67.7 & 0.955 & 70.4 & 66.1 & 0.454 \\
\hline CAD & 14.5 & 19.7 & 0.374 & 21.5 & 17.9 & 0.452 \\
\hline Hyperlipidemia & 18.2 & 18.5 & 0.952 & 19.6 & 18 & 0.729 \\
\hline $\mathrm{CHF}$ & 3.6 & 8.7 & 0.269 & II.2 & 6.3 & 0.138 \\
\hline CVD & 5.5 & 5.2 & 1.0 & 21.5 & 17.9 & 0.452 \\
\hline PVD & 1.8 & 2.2 & 1.0 & 0.9 & 2.8 & 0.280 \\
\hline Hypothyroidism & 10.9 & 11.6 & 0.879 & II.2 & 12.3 & 0.786 \\
\hline \multicolumn{7}{|l|}{ Laboratory data } \\
\hline Hemoglobin (g/dL) & $13.0 \pm 1.6$ & $12.9 \pm 1.4$ & 0.696 & $12.8 \pm 1.5$ & $13.1 \pm 1.4$ & 0.696 \\
\hline Fasting blood glucose (mg/dL) & $111.2 \pm 36.3$ & $103.9 \pm 30.7$ & 0.141 & $110 \pm 37.7$ & $102.5 \pm 27.9$ & 0.063 \\
\hline $\mathrm{HbA}_{\mathrm{Ic}}(\%)$ & $6.6 \pm 1.4$ & $7.0 \pm 1.1$ & 0.184 & $7.2 \pm 1.4$ & $6.7 \pm 1.0$ & 0.068 \\
\hline Albumin & $3.9 \pm 0.4$ & $4.1 \pm 0.3$ & 0.003 & $4.0 \pm 0.3$ & $4.1 \pm 0.3$ & 0.064 \\
\hline LDL-C (mg/dL) & $119.6 \pm 36.7$ & $130.2 \pm 36.3$ & 0.071 & $124.2 \pm 35.8$ & $130.9 \pm 37.2$ & 0.151 \\
\hline 25(OH)D (ng/mL) & $15.4 \pm 9.7$ & $20.1 \pm 12.2$ & 0.010 & $17.3 \pm 9.9$ & $19.2 \pm 10.7$ & 0.162 \\
\hline TSH $(\mu \mathrm{IU} / \mathrm{mL})$ & $1.7 \pm 1.7$ & $1.5 \pm 1.2$ & 0.291 & $1.6 \pm 1.4$ & $1.6 \pm 1.3$ & 0.932 \\
\hline Vitamin $B_{12}(p g / m L)$ & $519 \pm 300$ & $468.5 \pm 254.7$ & 0.210 & $492.9 \pm 272$ & $468.8 \pm 262.2$ & 0.463 \\
\hline Folic acid (ng/mL) & $9.3 \pm 5.9$ & $9.0 \pm 4.8$ & 0.722 & $8.7 \pm 5.2$ & $9.4 \pm 5.0$ & 0.247 \\
\hline eGFR (mL/min/I.73 m²) & $65.8 \pm 14$ & $73.7 \pm 20.7$ & 0.001 & $7 I . I \pm 20.8$ & $73.5 \pm 19$ & 0.325 \\
\hline
\end{tabular}

Notes: Data presented as mean \pm standard deviation unless stated otherwise. Data in bold indicates statistical significance.

Abbreviations: AST, active standing test; BMI, body mass index; CAD, coronary artery disease; CHF, chronic heart failure; COPD, chronic obstructive pulmonary disease; CVD, cerebrovascular disease; DM, diabetes mellitus; eGFR, estimated glomerular filtration rate; HUT, head-up tilt table test; LDL-C, low-density lipoproteins cholesterol; $\mathrm{OH}$, orthostatic hypotension; PVD, peripheral vascular disease; TSH, thyroid-stimulating hormone; 25(OH)D, 25-hydroxyvitamin D. 
Table 2 Comprehensive geriatric assessment measurements according to HUT and AST

\begin{tabular}{|c|c|c|c|c|c|c|}
\hline & \multicolumn{3}{|l|}{ HUT } & \multicolumn{3}{|l|}{ AST } \\
\hline & $\begin{array}{l}\mathrm{OH}(+) \\
n=55(19 \%)\end{array}$ & $\begin{array}{l}\text { OH(-) } \\
n=235 \text { (8 I \%) }\end{array}$ & $P$-value & $\begin{array}{l}\mathrm{OH}(+) \\
n=108(37 \%)\end{array}$ & $\begin{array}{l}\text { OH(-) } \\
n=182(63 \%)\end{array}$ & $P$-value \\
\hline MMSE & $22 \pm 5.8$ & $23.5 \pm 5.6$ & 0.246 & $23.9 \pm 5.9$ & $23.2 \pm 5.1$ & 0.520 \\
\hline COST & $21.4 \pm 6.7$ & $24.2 \pm 5.0$ & 0.014 & $24.5 \pm 4.8$ & $23.2 \pm 5.9$ & 0.184 \\
\hline YGDS & $3.1 \pm 3.2$ & $2.6 \pm 2.9$ & 0.323 & $2.7 \pm 2.8$ & $2.7 \pm 3.2$ & 0.999 \\
\hline POMA-balance & $12.2 \pm 3.5$ & $13.5 \pm 2.7$ & 0.014 & $13.2 \pm 3.2$ & $13.5 \pm 2.8$ & 0.384 \\
\hline POMA-gait & $9.3 \pm 2$ & $10.3 \pm 1.6$ & $<0.01$ & $10.1 \pm 1.8$ & $10.2 \pm 1.7$ & 0.570 \\
\hline BADL & $87.0 \pm 16$ & $92.2 \pm 11.7$ & 0.032 & $91.2 \pm 12.5$ & $91.5 \pm 13$ & 0.856 \\
\hline IADL & $8.2 \pm 5.1$ & $11.9 \pm 4.9$ & $<0.01$ & $1 \mathrm{I} \pm 5.3$ & $11.5 \pm 5$ & 0.429 \\
\hline MNA & $10.4 \pm 2.9$ & $11.4 \pm 2.0$ & 0.001 & | $1.3 \pm 2.4$ & II. $2 \pm 2.2$ & 0.552 \\
\hline
\end{tabular}

Notes: Data presented as mean \pm standard deviation. Data in bold indicates statistical significance.

Abbreviations: AST, active standing test; BADL, basic activity of daily living (0 [worst]-100 [best]); COST, cognitive state test (0 [worst]-30 [best]); HUT, head-up tilt table test; IADL, instrumental activity of daily living (0 [worst]-23 [best]); MMSE, mini-mental state examination (0 [worst]-30 [best]); MNA, mini nutritional assessment (0 [worst]-14 [best]); POMA, Tinetti performance-oriented mobility assessment (balance score (0 [worst]-16 [best]) and gait score (0 [worst]-12 [best]); YGDS, Yesavage geriatric depression score (15 [worst] 0 [best]).

activity of daily living were lower in patients with $\mathrm{OH}$ during HUT $(P<0.05$; Table 2).

The AST had a specificity of $65.5 \%$ and a sensitivity of $49.0 \%$ for identifying $\mathrm{OH}$ according to HUT. The positive predictive value and negative predictive value of AST were $25 \%$ and $84.6 \%$, respectively.

\section{Discussion}

Orthostatic BP changes determined by HUT might be of higher clinical significance than those determined by AST in older adults. It might be important that the evaluation of $\mathrm{OH}$ by HUT should be included in daily geriatric practice.

$\mathrm{OH}$ is a major geriatric syndrome, but it may be overlooked despite numerous complications such as mortality, ischemic stroke, falls, cognitive deficit, depression, and sleep disorders. ${ }^{12,22-25}$ Therefore, accurate diagnosis of $\mathrm{OH}$ is crucial in older adults. The prevalence of $\mathrm{OH}$, which is reported as $9.5 \%-37 \%$ by AST and $21 \%-51 \%$ by HUT in the current literature, varies according to the method used and patients' characteristics. ${ }^{19,26-31}$ However, in most of these studies, the prevalence was obtained by using either AST or HUT. Only two studies in the literature have compared AST and HUT as a method in the same sample of patients. ${ }^{19,32}$ Although Faraji et al obtained twofold higher $\mathrm{OH}$ prevalance during HUT than AST, the retrospective nature of the study, the lack of methods following one after another (AST and HUT), and extending HUT to the 40th minute may lead to different outcomes. ${ }^{32}$ Cooke et al retrospectively evaluated the cases between the age of 22 and 93 years, ${ }^{19}$ whereas in the present study, only older adults were included and revealed two different prevalances by two different methods in the same sample of patients. Furthermore, Rickards et al compared HUT with the squat-stand test and emphasized that active joint and muscle movements induce vasoconstriction in the blood vessels, causing an increase in transient ischemia and vasoactive metabolites in the muscles, which reduce venous return with compensatory vasodilatation in the lower extremity, resulting in more BP drop at baseline compared to HUT. ${ }^{33}$ The effort exerted by a number of older adults during transition from supine to upright position due to existing comorbidities and immobility may reduce venous return with similar mechanisms. Physiopathologic changes such as aging-induced decreased baroreflex sensitivity and renin angiotensin aldosterone levels may also have been associated with more $\mathrm{OH}$ prevalence for AST than HUT. ${ }^{34,35}$

Previous studies reported that $\mathrm{OH}$ might be associated with age, cognitive decline, malnutrition, renal failure, gait-balance disorders and recurrent falls, decline in daily living activities, hypoalbuminemia, and hypovitaminosis D. ${ }^{2,5,7-12,29,36,37}$ In the present study, most of these findings were similar to the results obtained by only HUT but not by AST. Based on the outcomes, it can be speculated that clinical reflection of $\mathrm{OH}$ during HUT might be more valuable in older adults. Furthermore, when the clinical importance of $\mathrm{OH}$ as a geriatric syndrome and the fact that the majority of patients with $\mathrm{OH}$ are asymptomatic are taken into account, ${ }^{4}$ the importance of reaching the correct diagnosis of $\mathrm{OH}$ by HUT is obvious in geriatric practice.

On the other hand, when HUT was used as the gold standard for comparison, the lower sensitivity, specificity, and positive predictive value of the AST method were determined. In this case, to strengthen the diagnosis of $\mathrm{OH}$, older adults should be verified with HUT, even in the presence of $\mathrm{OH}$ diagnosed by AST. To avoid overdiagnoses of $\mathrm{OH}$ by AST, auscultatory measurements of BP should be taken by a physician skilled in the technique recommended by the 
American Heart Association, ${ }^{38}$ or a digital blood sphygmomanometer can be preferred for BP measurements. In addition, large majority of older adults cannot change their positions easily and they exert efforts to sit and stand up from supine position during AST on account of existing comorbidities and mobility problems. Therefore, HUT seems to be a more objective method to diagnose $\mathrm{OH}$.

Our study has several limitations. The first is the absence of measurements with a digital BP-measuring device during AST to compare with HUT. The second is the exclusion of some elderly patients in view of contraindications for HUT. The powerful aspects of our study, however, include its prospective design, adequate sample size, and the use of HUT test for diagnosis and comparison with AST. Besides, all the participants are older adults, so our study population represents geriatric patients vigorously.

\section{Conclusion}

These results suggest that orthostatic BP changes determined by HUT seem to have higher clinical significance than those determined by AST in older adults. It is important that the evaluation of $\mathrm{OH}$ by HUT should be included in daily geriatric practice.

\section{Acknowledgment}

The authors thank Hulya Ellidokuz for statistical analysis.

\section{Disclosure}

The authors report no conflicts of interest in this work.

\section{References}

1. Feldstein C, Weder AB. Orthostatic hypotension: a common, serious and underrecognized problem in hospitalized patients. J Am Soc Hypertens. 2012;6(1):27-39.

2. Chen SY, Chen CH, Chang CM. [Management of orthostatic hypotension in the elderly]. Hu Li Za Zhi. 2010;57(5):89-95. Chinese [with English abstract].

3. Press Y, Punchik B, Freud T. Orthostatic hypotension and drug therapy in patients at an outpatient comprehensive geriatric assessment unit. J Hypertens. 2016;34(2):351-358.

4. Fedorowski A, Melander O. Syndromes of orthostatic intolerance: a hidden danger. J Intern Med. 2013;273(4):322-335.

5. Gupta V, Lipsitz LA. Orthostatic hypotension in the elderly: diagnosis and treatment. Am J Med. 2007;120(10):841-847.

6. Arbogast SD, Alshekhlee A, Hussain Z, McNeeley K, Chelimsky TC. Hypotension unawareness in profound orthostatic hypotension. Am J Med. 2009;122(6):574-580.

7. Galizia G, Convertino G, Testa G, Langellotto A, Rengo F, Abete P. Transient ischemic attack caused by delayed orthostatic hypotension in an elderly hypertensive patient. Geriatr Gerontol Int. 2012;12(3): 565-567.

8. McHugh JE, Fan CW, Kenny RA, Lawlor BA. Orthostatic hypotension and subjective sleep quality in older people. Aging Ment Health. 2012; 16(8):958-963.
9. Soysal P, Yay A, Isik AT. Does vitamin D deficiency increase orthostatic hypotension risk in the elderly patients? Arch Gerontol Geriatr. 2014; 59(1):74-77.

10. Richardson J, Kerr SR, Shaw F, Kenny RA, O’Brien JT, Thomas AJ. A study of orthostatic hypotension in late-life depression. Am J Geriatr Psychiatry. 2009;17(11):996-999.

11. Mehrabian S, Duron E, Labouree F, et al. Relationship between orthostatic hypotension and cognitive impairment in the elderly. J Neurol Sci. 2010;299(1-2):45-48.

12. Gangavati A, Hajjar I, Quach L, et al. Hypertension, orthostatic hypotension, and the risk of falls in a community-dwelling elderly population: the maintenance of balance, independent living, intellect, and zest in the elderly of Boston study. J Am Geriatr Soc. 2011;59(3):383-389.

13. Soysal P, Isik AT, Buyukaydin B, Kazancioglu R. A comparison of endstage renal disease and Alzheimer's disease in the elderly through a comprehensive geriatric assessment. Int Urol Nephrol. 2014;46(8):1627-1632.

14. Schatz IJ, Bannister R, Freeman RL, et al. Consensus statement on the definition of orthostatic hypotension, pure autonomic failure, and multiple system atrophy. Neurology. 1996;46(5):1470.

15. Weiss A, Grossman E, Beloosesky Y, Grinblat J. Orthostatic hypotension in acute geriatric ward: is it a consistent finding? Arch Intern Med. 2002; 162(20):2369-2374

16. Isik AT, Soysal P, Usarel C. Effects of acetylcholinesterase inhibitors on balance and gait functions and orthostatic hypotension in elderly patients with Alzheimer disease. Am J Alzheimers Dis Other Demen. 2016;31(7): 580-584.

17. Lampela P, Lavikainen P, Huupponen R, Leskinen E, Hartikainen S. Comprehensive geriatric assessment decreases prevalence of orthostatic hypotension in older persons. Scand J Public Health. 2013;41(4): 351-358.

18. Luukinen H, Koski K, Laippala P, Kivelä SL. Prognosis of diastolic and systolic orthostatic hypotension in older persons. Arch Intern Med. 1999; 159(3):273-280

19. Cooke J, Carew S, O'Connor M, Costelloe A, Sheehy T, Lyons D. Sitting and standing blood pressure measurements are not accurate for the diagnosis of orthostatic hypotension. QJM. 2009;102(5):335-339.

20. Task Force for the Diagnosis and Management of Syncope; European Society of Cardiology (ESC); European Heart Rhythm Association (EHRA); Heart Failure Association (HFA); Heart Rhythm Society (HRS), Moya A, Sutton R, Ammirati F, et al. Guidelines for the diagnosis and management of syncope (version 2009). Eur Heart J. 2009;30(21): 2631-2671.

21. Babacan-Yildiz G, Isik AT, Ur E, et al. COST: cognitive state test, a brief screening battery for Alzheimer disease in illiterate and literate patients. Int Psychogeriatr. 2013;25(3):403-412.

22. Chou RH, Liu CJ, Chao TF, et al. Association between orthostatic hypotension, mortality, and cardiovascular disease in Asians. Int $J$ Cardiol. $2015 ; 195: 40-44$

23. Jodaitis L, Vaillant F, Snacken M, et al. Orthostatic hypotension and associated conditions in geriatric inpatients. Acta Clin Belg. 2015;70(4): 251-258.

24. Soysal P, Aydin AE, Koc Okudur S, Isik AT. When should orthostatic blood pressure changes be evaluated in elderly: 1st, 3rd or 5th minute? Arch Gerontol Geriatr. 2016;65:199-203.

25. Angelousi A, Girerd N, Benetos A, et al. Association between orthostatic hypotension and cardiovascular risk, cerebrovascular risk, cognitive decline and falls as well as overall mortality: a systematic review and meta-analysis. J Hypertens. 2014;32(8):1562-1571.

26. Gibbons CH, Freeman R. Delayed orthostatic hypotension: a frequent cause of orthostatic intolerance. Neurology. 2006;67(1):28-32.

27. Gurevich T, Machmid H, Klepikov D, Ezra A, Giladi N, Peretz C. Head-up tilt testing for detecting orthostatic hypotension: how long do we need to wait? Neuroepidemiology. 2014;43(3-4):239-243.

28. Kim HA, Lee H, Park KJ, Lim JG. Autonomic dysfunction in patients with orthostatic dizziness: validation of orthostatic grading scale and comparison of Valsalva maneuver and head-up tilt testing results J Neurol Sci. 2013;325(1-2):61-66. 
29. Fedorowski A, Burri P, Melander O. Orthostatic hypotension in genetically related hypertensive and normotensive individuals. J Hypertens. 2009; 27(5):976-982.

30. Hartog LC, Cimzar-Sweelssen M, Knipscheer A, et al. Orthostatic hypotension does not predict recurrent falling in a nursing home population. Arch Gerontol Geriatr. 2017;68:39-43.

31. Enrique Asensio L, Andrea Aguilera C, Maria de los Angeles Corral C, et al. Prevalence of orthostatic hypotension in a series of elderly Mexican institutionalized patients. Cardiol J. 2011;18(3):282-288.

32. Faraji F, Kinsella LJ, Rutledge JC, Mikulec AA. The comparative usefulness of orthostatic testing and tilt table testing in the evaluation of autonomic-associated dizziness. Otol Neurotol. 2011;32(4):654-659.

33. Rickards CA, Newman DG. A comparative assessment of two techniques for investigating initial cardiovascular reflexes under acute orthostatic stress. Eur J Appl Physiology. 2003;90(5-6):449-457.
34. Low PA. Prevalence of orthostatic hypotension. Clin Auton Res. 2008; 18 (Suppl 1):8-13.

35. Okada Y, Galbreath MM, Shibata S, et al. Relationship between sympathetic baroreflex sensitivity and arterial stiffness in elderly men and women. Hypertension. 2012;59(1):98-104.

36. Ometto F, Stubbs B, Annweiler C, et al. Hypovitaminosis D and orthostatic hypotension: a systematic review and meta-analysis. J Hypertens. 2016; 34(6):1036-1043.

37. Robertson D. The pathophysiology and diagnosis of orthostatic hypotension. Clin Auton Res. 2008;18 (Suppl 1):2-7.

38. Curb JD, Labarthe DR, Cooper SP, Cutter GR, Hawkins CM. Training and certification of blood pressure observers. Hypertension. 1983;5(4): 610-614.
Clinical Interventions in Aging

\section{Publish your work in this journal}

Clinical Interventions in Aging is an international, peer-reviewed journal focusing on evidence-based reports on the value or lack thereof of treatments intended to prevent or delay the onset of maladaptive correlates of aging in human beings. This journal is indexed on PubMed Central, MedLine,

\section{Dovepress}

CAS, Scopus and the Elsevier Bibliographic databases. The manuscript management system is completely online and includes a very quick and fair peer-review system, which is all easy to use. Visit http://www.dovepress. com/testimonials.php to read real quotes from published authors. 